\title{
Stereodivergent Synthesis of Chiral Amino Alcohols by Copper(I) Catalyst
}

\section{Category}

Metal-Catalyzed Asymmetric

Synthesis and

Stereoselective

Reactions

\section{Key words}

copper catalysis

amino alcohols

hydrosilylation

hydroamination

stereodivergent synthesis

Cond. B $\mathrm{Cu}(\mathrm{OAc})_{2}(5 \mathrm{~mol} \%),(S)$ - or $(R)-\mathrm{L} 1(5.5 \mathrm{~mol} \%)$ $(\mathrm{MeO})_{2} \mathrm{MeSiH}\left(3-5\right.$ equiv), THF, $-60^{\circ} \mathrm{C}, 15 \mathrm{~h}$ then aminating reagent $\left(1.5\right.$ equiv), $55^{\circ} \mathrm{C}, 70 \mathrm{~h}$

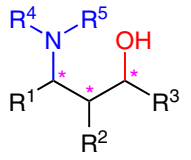
dr up to $>20: 1$

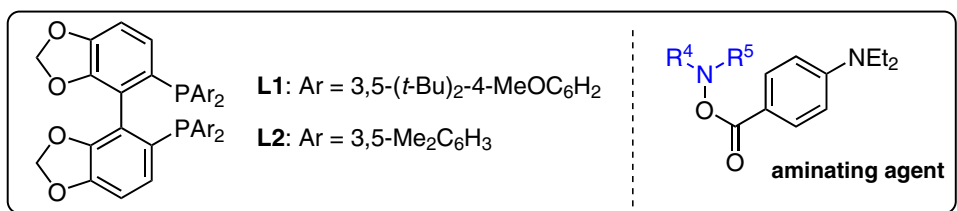

\section{Selected examples:}<smiles>OC[C@H](Cc1ccccc1)[C@@H](c1ccccc1)N(Cc1ccccc1)Cc1ccccc1</smiles>

Cond. A, $(Z),(R)-\mathrm{L} 1$ $95 \%$ yield, $>99 \%$ ee, $\mathrm{dr}>20: 1$

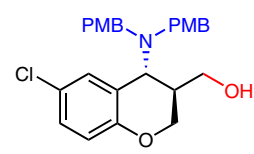

Cond. A, $(E),(S)$-L1

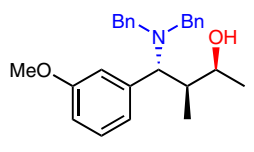

Cond. B, $(E),(S)-$ L1 1\% yield, $>99 \%$ ee, $\mathrm{dr}>20:$

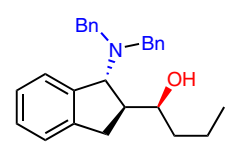

Cond. B, $(E),(S)$-L1 $67 \%$ yield, $>99 \%$ ee, $\mathrm{dr}>10: 1$

Stereodivergent synthesis of all eight isomers of amino alcohols: ${ }^{a}$
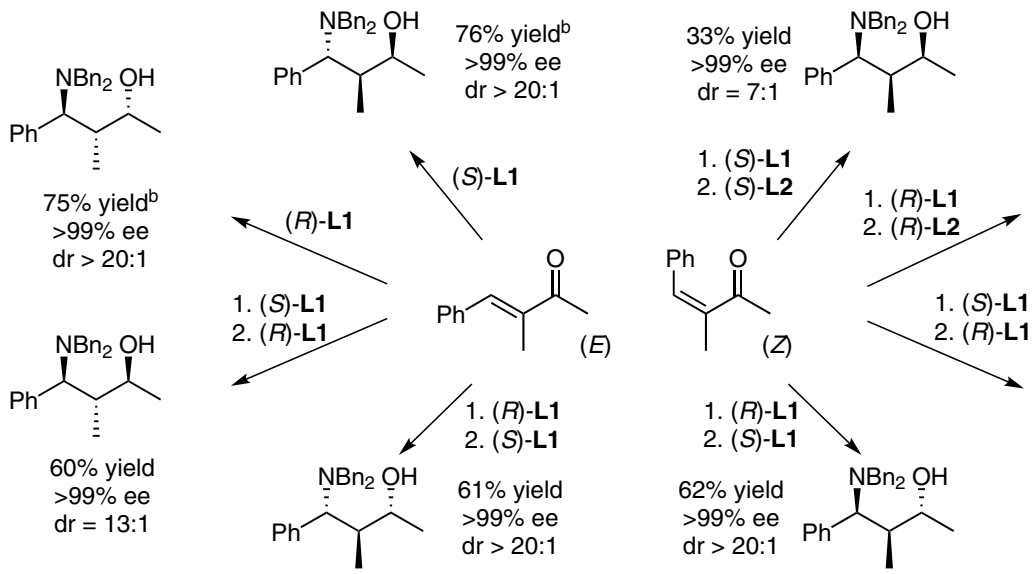

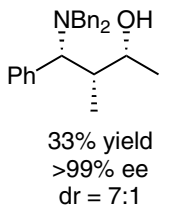

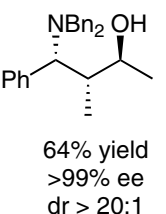

${ }^{a}$ Hydroamination step was carried out after purified hydrosilylated product. ${ }^{\mathrm{b}}$ One-pot procedure.

Significance: The authors report the stereodivergent synthesis of amino alcohols bearing up to three contiguous stereocenters by copper-catalyzed hydrosilylation/hydroamination from readily available enals or enones. The reported method allows access to all stereoisomers by choosing the $(E) /(Z)$-isomer of the substrate and the $(R) /(S)$ enantiomer of the ligand.

SYNFACTS Contributors: Mark Lautens, Kosuke Yamamoto Synfacts 2016, 12(07), 0695 Published online: 17.06.2016 Dol: 10.1055/s-0035-1562311; Reg-No.: L06616SF
Comment: Various enals, enones, and aminating reagents, especially those containing acetals, phenols, esters and heteroaromatics, were tolerated in the reported method, affording chiral amino alcohols in good to high yield with excellent diastereo- and enantioselectivity. Under the ligand exchange protocol, eight stereoisomers were obtained in moderate to good yield with excellent stereoselectivity. 